EPiC Series in Education Science
Volume 3, 2020, Pages 269-273
Proceedings of the MIT LINC 2019 Conference

\title{
Understanding Lived Experiences of Faculty in an Increasingly Digitized World
}

\author{
Tiffany L. Wong ${ }^{1}$, Selen Türkay ${ }^{2}$ and Drew Lichtenstein ${ }^{1}$ \\ ${ }^{1}$ Harvard University, Cambridge, MA, USA \\ ${ }^{2}$ Queensland University of Technology, Brisbane, QLD, Australia \\ tiffany_wongeharvard.edu, selen.turkayequt.edu.au, \\ drew_lichtenstein@harvard.edu
}

\begin{abstract}
Although universities and their faculty design courses for periodic learning, the "new learning society," an increasingly diverse, mobile population is inexorably shifting to a model of continuous, self-directed, lifelong learning. Hence, the effective instructional practices that emerge through the role of the MOOC instructor have lasting value, whether the trend of MOOCs endures, or not. Understanding faculty experiences can inform online teaching as well as facilitate the success of MOOCs and other online offerings within and beyond the university. It can also help both faculty and learners thrive in a new learning society. As part of a larger study, this paper reports on the impact of online teaching on instructors' pedagogical approaches. A key finding is that instructors improved their residential teaching by incorporating MOOC material into their courses; online format also forced instructors to think of both their subject matter and the presentation of their content in better and more inclusive ways.
\end{abstract}

\section{Background}

Since the term MOOC (Massive Open Online Course) was coined in 2008, a wide range of online learning experiences have been defined under the term. Simultaneously, traditional forms of online learning, characterized by degree granting semester long courses have continued to coexist. Few prior studies examined how teaching online courses, including MOOCs impact instructor's overall pedagogical approaches. Najafi et al.' (2015) study found MOOC design and instruction entailed two main pedagogical implications: enhancing the clarity of content (e.g. discipline specific terminology, close attention to establish clear goals) and restructuring instruction in credit courses. Course redesign may result in a flipped classroom format using MOOC material or integrating frequent feedback, discussion, and peer-assessment within the curriculum (Holland \& Tirthali, 2014; Lowenthal, Snelson, \& Perkins, 2018). There is also evidence that teaching an online course may focus instructors on learning processes (Kearns, 2016). 
This study focuses on lived experiences of online instructors teaching three types of online offerings: 1) xMOOCs, 2) traditional degree granting online extension schools, and 3) paid professional development courses at the medical school.

xMOOCs place the instructor and learner in traditional pedagogical roles, with an emphasis on didactic instruction, transmitting information from instructor to learner (Ross et al., 2014, p.59). To date, 129 unique courses have been created through HarvardX; each may have three versions and multiple re-runs. While one of the goals of HarvardX is to improve residential teaching at Harvard (HarvardX website, 2018), this potential impact has not been empirically studied. HarvardX support faculty with a team of instructional development and video production experts that work closely with instructors to create their MOOC.

Online extension school courses are generally semester long, undergraduate and graduate level courses that reach a broader more inclusive, less traditional group than the university's college, graduate or professional schools. Instructors work with instructional designers and video production experts to create their courses. As a degree granting institution, the school aims to "offer multiple paths to enrollment" (DCE website). Some learners take a single course to fill a knowledge gap, others take a set of courses to learn new skills through a certificate or degree.

The online medical school (HMx) courses aim to "help learners focus on the understanding and application of key scientific principles. Whether you're catching up or getting ahead-or just looking for a new perspective on core medical concepts" (HMX website). HMX also hopes to reach a wider audience than those in the residential medical school including, pre-health/post-baccalaureate, medical professionals, high school students and other professionals. Unique to HMX, in addition to content and video experts, HMX also has in-house medical \& scientific illustrators and animators.

\section{Methods}

Semi-structured interviews were conducted in person, via video conferencing or on the phone by an external researcher to maintain an unbiased approach. The protocol included seven open ended main questions (e.g., "What was your experience like developing your MOOC/online course?") with multiple follow-up questions (e.g., "What do you wish you could have done differently"). The interviews ranged between 20 to 45 minutes. The interview data were audio recorded, transcribed and reviewed based on the research aims and imported into Dedoose software for analysis. An inductive approach was used to analyze data (Creswell, 2012; Thomas, 2006) by coding interviews and transcribing code segments relevant to research questions; collapsing codes into emergent themes and categories; and preparing descriptive accounts of major and minor themes from the data.

We interviewed 21 faculty: 9 taught MOOCs, 5 taught an HMX course and 7 taught at DCE. Faculty were from different disciplines and every Harvard school, except the school of dentistry. The identity of the participants is kept confidential by using pseudonyms. No reference is made to their course title, or the exact time period of course offering.

\section{Findings}

Instructors discussed the ways their online teaching informed their residential teaching and vice versa. Indeed, echoing Peters (2018), MOOC's indelible value may be in teaching the teachers that create them. By working with instructional designers, education researchers and creative professionals, instructors are able to create more accessible, scientifically driven learning instances, many of which have applications in residential classrooms. For Aaron who taught a HarvardX course, it is about "...eliminating the distinction between teaching online and teaching here [residential]. It's all one 
enterprise." According to Aaron, his work online improved his teaching in person and his in person teaching furthered his teaching online.

The global nature of learners allows instructors to get a broad perspective without going to each country. MOOCs provide a mechanism for instructors to study a phenomenon by connecting to a diverse body of learners online. Although Brady enjoys immersing himself in the situation in his travels, he felt, "But this $[\mathrm{MOOC}]$ is a fairly efficient time and cost wise way of tapping the ability to do the experiences" (Brady, HarvardX).

As an astrophysicist, the online platform allowed Nora to collaborate with colleagues in diverse disciplines from archeology to economics to physics. She created a freshman seminar in parallel to the MOOC. The MOOC and subsequent freshman seminar provided her the opportunity see connections between an ancient Mesopotamian divination book to "parallels later in physics and in astrophysics. So being able to make those connections for people comes with knowing a lot about the subject matter. And so it's not really how does HarvardX affect the seminar, or how does the seminar affect HarvardX? It's sort of how does working more on a topic let you present it in different ways to different audiences" (Nora). Below are some specific ways instructors improved their pedagogy through teaching online.

\subsection{Online teaching encouraged instructors to articulate learning objectives clearly}

Across the three online learning offerings, instructors mentioned online teaching encouraged them crystalize explicit learning objectives. James (DCE) stated that "the online experience kind of forced me into that." Similarly, Julia (HMX) found planning out objectives a good exercise and helped her get into a habit where "....it comes a lot more naturally now. To sit down at the beginning and do something like write out learning objectives, to think about interweaving, to think about how you can bring concepts back throughout the course to try to reinforce the earlier concepts and help them to build new connections." Angela also from HMX added the influence of online teaching is bigger than she thought it had been and encouraged her to think about her role in teaching online "... It really made me think about what I'm teaching or what I'm saying. If it's that I go back into a classroom. That I'm being really, really clear on what I'm saying as I'm teaching or presenting. That's something that we really strive for and really pinpoint that we're getting a point across very clearly. So that's something I would definitely take back to classroom."

\subsection{Online teaching provided immediate feedback to instructors}

Instructors mentioned the feedback loops that allowed them to customize courses to their students' level of knowledge and needs. They also mentioned reflecting on and being more aware of their teaching strategies and improving their pedagogy by re-watching themselves teach. Victor who teaches a HarvardX MOOC reflected "Yeah, I mean, I'm much more aware now, having viewed all my stuff." Instructors are able to get immediate feedback and make adjustments because they could browse all their content and see "...that some parts of the course were much harder than we meant to be. And it was because we weren't preparing students properly for what was coming in later modules" (Shawn DCE). In a similar vein, the digital tool made it easier for Aaron (HarvardX) to "get feedback from the students and to integrate their response in a variety of different ways..." in his teaching and assessment. He added receiving a sense of students' understanding gave him a basis to respond them as well.

\subsection{Online teaching informs active, discussion based learning \& provides new resources}

Instructors lecture less in their residential courses after creating a MOOC, switching to more active learning methods. Aaron, who taught his course for many years prior to creating a MOOC, notes 
teaching his MOOC led him to organize more small group discussions more rather than lecturing. Sarah echoes, "I teach my residential courses differently now...I teach more with examples and cases and less lecturing in my classes... we're just much more interactive in class because I didn't have to tell them as much as I used to tell them." Not only did Sarah "flip" her classroom but she added the MOOC "would essentially become the prerequisite for every single thing I teach, then it just sort of happens...you feel less resentful of the amount of time that it takes do the HarvardX course because you realize it's helping your other children (meaning her other online and residential offerings)" (Sarah).

Instructors take advantage of the affordances of multimedia and diversity of resources created for MOOCs as a repository of materials for residential classes. Ryan created videos that provided context for case based discussions, by creating "interview-based segments with really cool people or really cool places. And that's the kind of thing that in a bricks and mortar course, I could not get those people to come every year and the like. So by recording it once in a high quality environment, I can also reuse some of those materials for bricks and mortar courses."

\subsection{Online teaching made residential learning more accessible}

Instructors believe that their residential classes are more accessible now thanks to online courses through the diverse materials and the experiences gained teaching a wide range of learners. Brian, additionally, felt teaching a MOOC helped "level the playing field" in his residential course "...Because not only did it help me understand what can be hidden prerequisites in a given course, but those very materials I now make available to my on campus students" (Brian).

However, the integration of content into residential classes is not always straightforward. Eric spoke about his struggles of finding best ways to do such integration, and how to use videos in his residential courses in a meaningful way. Brady, also found it difficult to create a synergy between his residential course and MOOCs, "...it would be fun what the 20,30, 40, 50000 people around the world who had signed on were saying about that session and bring that into the physical classroom. It was very hard to coordinate that, so that didn't really work out."

\section{Discussion}

Although universities and their faculty design courses for periodic learning, educational institutions are inexorably shifting to a model of continuous, lifelong learning. Hence, the effective instructional practices that are emerging through the role of the online instructor has lasting value whether the trend of MOOCs endures or not (Siemens et al., 2013). Understanding faculty experiences can inform institutional leaders to online program implementation as well as facilitating the success of MOOCs as an educational format (Ross et al., 2014).

The findings from this study both support and expand on the small body of literature about online instructor experiences and perspectives of teaching online courses. A key finding was that instructors improved their residential teaching by incorporating online teaching material into their courses and began to incorporate principles of Universal Design Learning. Teaching online encouraged faculty to be more reflective in their pedagogical approaches, and to take advantage of the online platform, forcing instructors to think of both their subject matter, learning outcomes, and the presentation of their content in new and innovative ways which transformed classrooms into more inclusive learning environments.

Limitations include selecting faculty from a single institution, although they were from wide range of schools. This study focused on xMOOCs, degree granting and non-degree granting instructor-led online experiences. Other types of MOOCs could afford different instructional design strategies and would attract instructors with different views. Future research may consider investigating instructor experiences across different types of MOOCs and other online experiences. 


\section{References}

Anderson, T. (2013). Promise and/or peril: MOOCs and open and distance education. Commonwealth of learning.

Creswell, J. W. (2012). Educational research. Planning, conducting, and evaluating quantitative and qualitative research.

Dedoose Qualitative Analysis software. https://www.dedoose.com/

Kearns, L. R. (2016). The experience of teaching online and its impact on faculty innovation across delivery methods. The Internet and Higher Education, 31, 71-78. https://doi.org/10.1016/j.iheduc.2016.06.005

Lowenthal, P. R., Snelson, C., \& Perkins, R. (2018). Teaching Massive, Open, Online, Courses (MOOCs): Tales from the front line. International Review of Research in Open and Distributed Learning, 19(3), 19.

Najafi, H., Rolheiser, C., Harrison, L., \& Håklev, S. (2015). University of Toronto instructors experiences with developing MOOCs. The International Review of Research in Open and Distributed Learning, 16(3). https://doi.org/10.19173/irrodl.v16i3.2073

Peters, D., (2018) MOOCs are not dead, but evolving. On the 10th anniversary of the first massive open online course, they are more numerous than ever. https://www.universityaffairs.ca/news/news-article/moocs-not-dead-evolving/

Ross, J., Sinclair, C., Knox, J., Bayne, S., \& Macleod, H. (2014). Teacher Experiences and Academic Identity: The Missing Components of MOOC Pedagogy, 10(1), 14.

Siemens, G. (2005). Connectivism - A learning theory for the digital age. International Journal of Instructional Technology and Distance Learning, 2(1), 3-10.

Siemens, G., Irvine, V., \& Code, J. (2013). Guest editors' preface to the special issue on MOOCs: an academic perspective on an emerging technological and social trend. Journal of Online Learning and Teaching, 9(2), iii.

HarvardX website, The President and Fellows of Harvard College (2018).

https://harvardx.harvard.edu/

HMX website, The President and Fellows of Harvard College (2018).

https://onlinelearning.hms.harvard.edu/hmx/about/

DCE website, The President and Fellows of Harvard College (2018). www.dce.harvard.edu/

Thomas, D. R. (2006). A general inductive approach for analyzing qualitative evaluation data. American journal of evaluation, 27(2), 237-246. 